Archivio Mediceo avanti il Principato. The wide range of petitioners encountered here show that Lorenzo maintained personal ties with Florentines of all social and economic classes; here, more than anywhere, he might be shown to be the "princely citizen" Kent envisions.

Well-written and clearly edited, these essays are the work of a master reviewing a fruitful career. James's editing is primarily for consistency and clarity in language and formatting; additional bibliographies have been added, along with unpublished manuscripts in footnotes. The archival work here is thorough and clear-headed, and Kent is careful to balance assertions with evidence, or with tentative hedging where evidence is thin, and to support his arguments with ample reference to a wide body of English, French, and Italian scholarship. Minor repetitions or confusions between essays reflect the fact that they were written in different periods, for different purposes, and do not detract from readability. Demonstrating how Lorenzo's rule over Florence was the product of a lifetime's training and practice, Kent shows how Il Magnifico was able to balance the contradictory roles of prince and citizen.

COLIN ROSE

University of Toronto

\title{
Kusukawa, Sachiko.
}

Picturing the Book of Nature: Image, Text, and Argument in SixteenthCentury Human Anatomy and Medical Botany.

Chicago: University of Chicago Press, 2012. Pp. xvii, $331+120$ ill. ISBN 978-0226-46529-6 (hardcover) \$45.

It is often noticed that Andreas Vesalius's De humani corporis fabrica and Nicolaus Copernicus's De revolutionibus orbium coelestium were published in the same year, 1543, and the two books are sometimes paired together as marking the beginning of a new era. Less attention has been devoted to the fact that Vesalius's book followed Leonhart Fuchs's De historia stirpium (1542) by only one year. While scholars have acknowledged both Fuchs's and Vesalius's impressive visual and intellectual accomplishments, they don't usually consider their works under the same rubric. Picturing the Book of Nature pairs them as the representatives of a moment in which images became "integral to the object, 
method, and authority of scholarly knowledge about nature in the sixteenth century" (3). Kusukawa's remarkable and beautifully illustrated book sets the agenda right upfront: it is "concerned with the role of pictures in printed books in the formation and establishment of new knowledge about nature" (1). The bulk of the book examines how Conrad Gessner as well as Fuchs and Vesalius placed pictures at the centre of their understanding of nature and saw them as integral to the task of reviving classical knowledge. While the book insightfully reconstructs how the project unfolded and was eventually accomplished, it also sheds light on the obstacles encountered along the way. The text is divided into three sections: part 1 considers the practices and constraints that accompanied the process of printing images in learned books; part 2 focuses on the inclusion of images of medicinal plants in botanical texts; and part 3 examines Vesalius's famous anatomical pictorial project.

In sixteenth-century Europe, botany and anatomy were part of the study of medicine and had seasonal constraints: botany was carried out in the summer in botanical gardens; anatomy in the winter, when cold temperatures allowed better preservation of cadavers. However, things partly changed when botanical and anatomical books started to include pictures that supported the elaboration of universal arguments. To be sure, the process of integration of pictures into printed books was not smooth. Kusukawa reconstructs how the production of illustrated books was affected by practical and economic factors, such as the high cost of paper and of printing images. She also highlights how such factors could interfere with the authors' efforts to maintain a degree of control over their works. For instance, authors felt vulnerable to widespread practices of copying that could undermine the value of their works, and sought to protect their books, sometimes via legal means, though often with mixed results. In the end, Fuchs's and Vesalius's success in their scholarly enterprises involved contributing financially to the production of their books and creating fruitful collaborations with skilled artists. Indeed, authors' relationships with artists were of critical importance to their enterprises, and Kusukawa discusses in detail how these collaborations were shaped and reflected in the final product. She points out that the relationship between pictures and observational practices was neither simple nor straightforward. Rather, since pictures were central to the investigation and interpretation of nature, their creation presupposed choices that could support their function as media of "a powerful form of argument-a visual argument encompassing both demonstration and persuasion" (251). For instance, while 
seeking to "revive pristine knowledge of medicinal plants" (123), Fuchs had to deal with the challenge that knowledge about plants conveyed by ancient sources could be partial and, at the same time, his world contained plants unknown to the ancients. His creation of a "complete" picture (pictura absolutissima) sought to tackle such challenges by amalgamating variations, bridging between ancient and contemporary knowledge, and "ultimately adjudicating between competing opinions among ancients and contemporary authorities" (122). Not surprisingly, the use of pictures was not uncontroversial, and Kusukawa traces how images became themselves part of scholarly disputes, raising questions and stimulating discussions about what they stood for and about the advantages and disadvantages of using them in printed books. In the case of Vesalius, Kusukawa reconstructs how pictures played a part in the famous controversy over bloodletting, where they crucially supported his insights into the most effective way to let blood. Likewise, she shows how Vesalius's views in the Fabrica were supported by the integration of words and images, and how pictures made it possible to convey knowledge of the canonical body (homo absolutus), the perfectly proportioned body which, according to Vesalius, had to be studied in public anatomy lessons but could not easily be found in nature.

Kusukawa's masterly crafted book is an impressive achievement that promises to trigger further inquiry into how pictures became important tools to support scholars' ambitions and arguments in printed books. Kusukawa interestingly draws attention to how religious motivations underpinned Gessner's study of nature through images (176). She also points out that Vesalius's De humani corporis fabrica replicates the title of a tract by the seventh-century Galenic and Christian author Theophilus Protospatharius, who "viewed the human body as a creature of God" (204). Her fascinating observation may whet the reader's appetite to delve further into the religious dimension of Vesalius's pictorial enterprise. The book's focus on Northern and Central Europe may stimulate curiosity about the role of pictures in printed books elsewhere. Likewise, future research may explore how pictures that were created in close association with words, as in the Fabrica, ended up taking a life of their own. In short, many will benefit from this book's lucid and illuminating insights: not only historians of science and medicine but also scholars interested in visual culture, book history, and Renaissance studies as a whole.

LUCIA DACOME

University of Toronto 